\title{
Bacillary band ultrastructure of the fish parasite Capillaria pterophylli (Nematoda: Capillariidae)
}

\author{
Zdeňka Žd’árská and Jana Nebesářová
}

Institute of Parasitology, Academy of Sciences of the Czech Republic, Branišovská 31, 37005 České Budějovice, Czech Republic

Key words: Nematoda, Capillaria pterophylli, bacillary band, ultrastructure

\begin{abstract}
In Capillaria pterophylli Heinze, 1933, two lateral bacillary bands extend along the whole body in female and male worms. A ventral bacillary band is present in females only. The bacillary bands consist of glandular and non-glandular cells, and in the region between the nerve ring and the end of the stichosome, ciliated sense receptors in tight connection with gland cells are present.
\end{abstract}

The ultrastructure of the bacillary band of trichuroid nematodes studied earlier indicated that the region is a modified hypodermal chord containing glandular and non-glandular cells (Wright 1963, 1968, Sheffield 1963, Jenkins 1969, Bruce 1970, McDarby et al. 1987) and, occasionally, neurons and sense receptors (Wright 1968, Jenkins 1969, Wright and Chan 1973).

According to an older systematic arrangement the ultrastructure of bacillary bands has been studied in the genus Capillaria Zeder, 1800 s. 1., Trichuris Roederer, 1761, and Trichinella, Railliet, 1895. In the recent accepted conception of Moravec (1982), of a new systematic arrangement of nematodes of the family Capillariidae, Capillaria hepatica (Bancroft, 1893) does not belong to the genus Capillaria s. s., but to the genus Calodium Dujardin, 1845, and Capillaria catostomi (Pearse, 1924) to the genus Pseudocapillaria Freitas, 1959. Therefore, in the new systematic arrangement, our study represents the first description of the bacillary band ultrastructure of the genus Capillaria. Species of the genus Capillaria and Pseudocapillaria are intestinal parasites, whereas species of the genus Calodium parasitise parenchymal organs.

\section{MATERIALS AND METHODS}

Females and males of Capillaria pterophylli Heinze,1933 collected from the intestine of the angel fish Pterophyllum scalare (Lichtenstein) were washed in saline, fixed in $0.1 \mathrm{M}$ phosphate buffer ( $\mathrm{pH} \mathrm{7.2)} \mathrm{for} 2 \mathrm{~h}$ at $4^{\circ} \mathrm{C}$, postfixed for $2 \mathrm{~h}$ at $4^{\circ} \mathrm{C}$ in $1 \% \mathrm{OsO}_{4}$, dehydrated through an alcohol series and embedded in Durcupan via acetone. Series of ultrathin sections were cut using a Reichert-Jung Ultracut E ultramicrotome, double-stained with uranyl acetate and lead citrate and viewed in a TEM JEOL 1010 operated at $80 \mathrm{kV}$. Semi-thin sections were stained in toluidin blue.

\section{RESULTS}

In C. pterophylli two rather wide lateral bacillary bands extend along the whole body of male, whereas three bands occur in female, two lateral and one ventral (Fig. 1). The bacillary bands are composed through the whole length of two types of cells, the gland cells and the non-glandular cells (Figs. 1-4). In the bacillary bands anterior region only, between the level of the nerve ring and the most posterior stichocyte of the stichosome, ciliated sensory receptors are present (Figs. 5-9).

\section{Gland cell structures}

The gland cells (Figs. 2-4) of flat oval form with filamentous electron-lucid content penetrate the cuticle. This results in a surface perforation termed cuticular pore. The cuticular pore and the pore chamber are filled with extracellular filamentous material (Figs. 2, 3). No cap or plug formation was observed. The basal region of the cell rests on the basal lamina. The basal plasmalemma forms only few invaginations. The gland cells are separated from the cuticle by a bacillary sheath. The apical plasmalemma is highly infolded forming thus a lamellar apparatus reaching the pore chamber (Figs. 1-4). The electron-lucid cytoplasm of the gland cells contains fine filamentous material, few dense bodies, mitochondria and a nucleus at the basal part (Figs. 3, 4).

The non-glandular cells, few in number, enclose the proximal and basal parts of the gland cells (Fig. 3). It is possible that their processes form the bacillary sheath above the gland cells. The non-glandular cells interdigitate with the basal part of the gland cells making it difficult to distinguish the cytoplasm of both cell types. The electron-dense cytoplasm of the nonglandular cells contains $\beta$-particles of glycogen, few mitochondria, and at the base a nucleus. 

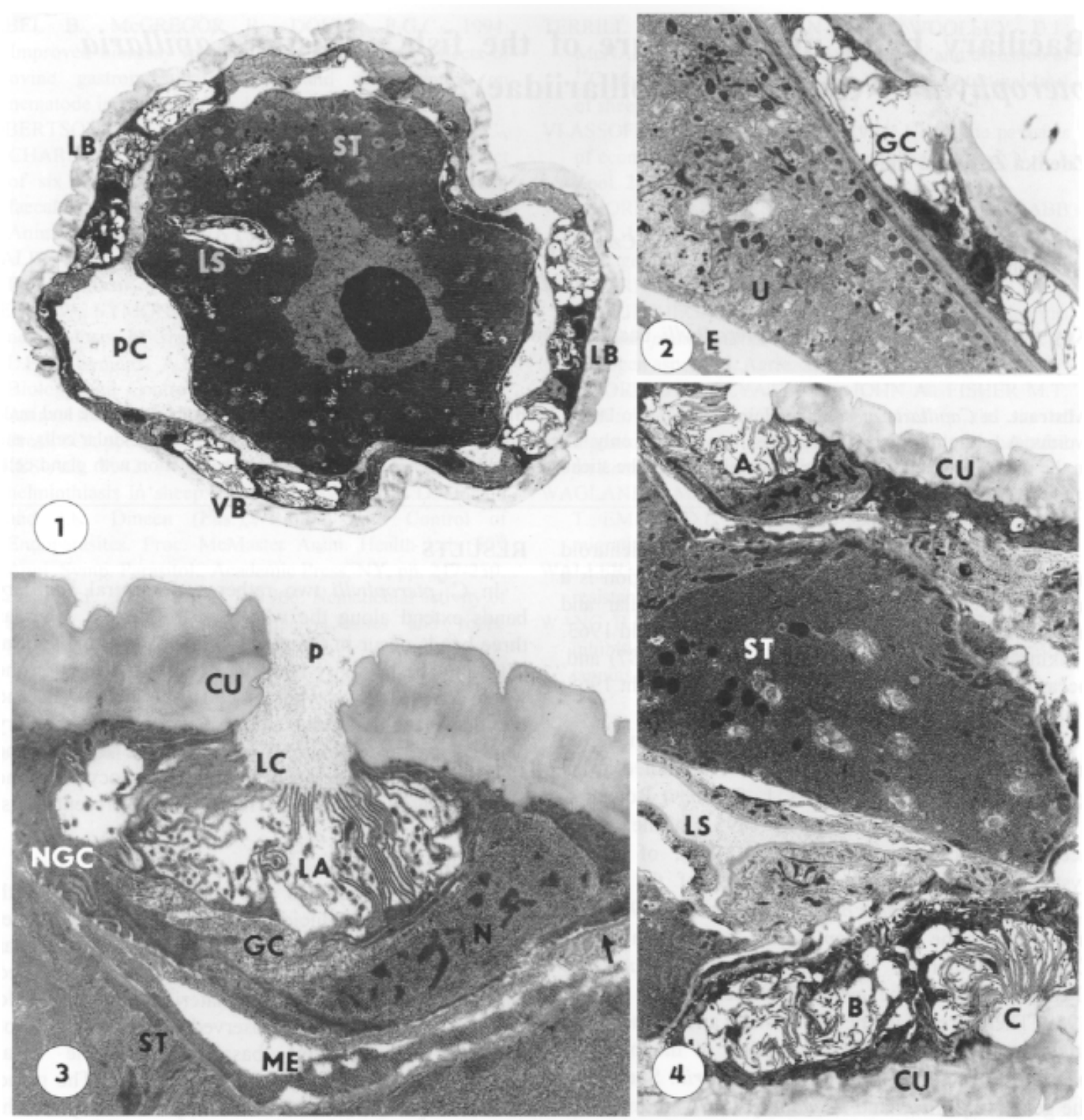

Figs. 1-4. Capillaria pterophylli, female. Transmission electron micrographs. Fig. 1. Cross section of the worm at the level of the last stichocyte (ST) of the stichosome demonstrating one ventral (VB) and two lateral (LB) bacillary bands. LS - lumen of stichosome, PC - pseudocoelom, $\times 2650$. Fig. 2. Bacillary band gland cells $(\mathrm{GC})$ at the level of uterus $(\mathrm{U}) . \mathrm{E}-\mathrm{egg}$ shell, $\times 4450$. Fig. 3. Bacillary band gland cell at the level of the stichosome (a serial section to the gland cell A in Fig. 4). CU - cuticle, GC cytoplasm of the gland cell, N - nucleus, LA - lamellar apparatus, LC - pore chamber, P - pore, NGC - cytoplasm of nonglandular cell, arrow - basal lamina, ME - processus of a myoepithelial cell surrounding the stichocyte $(\mathrm{ST}), \times 15300$. Fig. 4 . Tangential section through the worm at the level of the middle part of stichosome demonstrating three bacillary band gland cells (A, B, C). CU - cuticle, ST - stichocyte, LS - lumen of stichosome, $\times 6450$.

\section{Sensory structures}

Ciliated sense receptors are present in tight connection with the gland cells in the anterior end of the bacillary bands, i.e. at the level of the nerve ring and the last stichocyte of the stichosome. It is very difficult to follow the cytoplasmic parts of the neurons, but the cilium-derived sensory processes can be traced very well among the bacillary band gland cell structures. The modified ciliary parts of the sense receptors are localised among the lamellae of the lamellar apparatus (Figs. 5-9). One to four cilium-derived processes project into a single gland cell. The processes do not extend out 

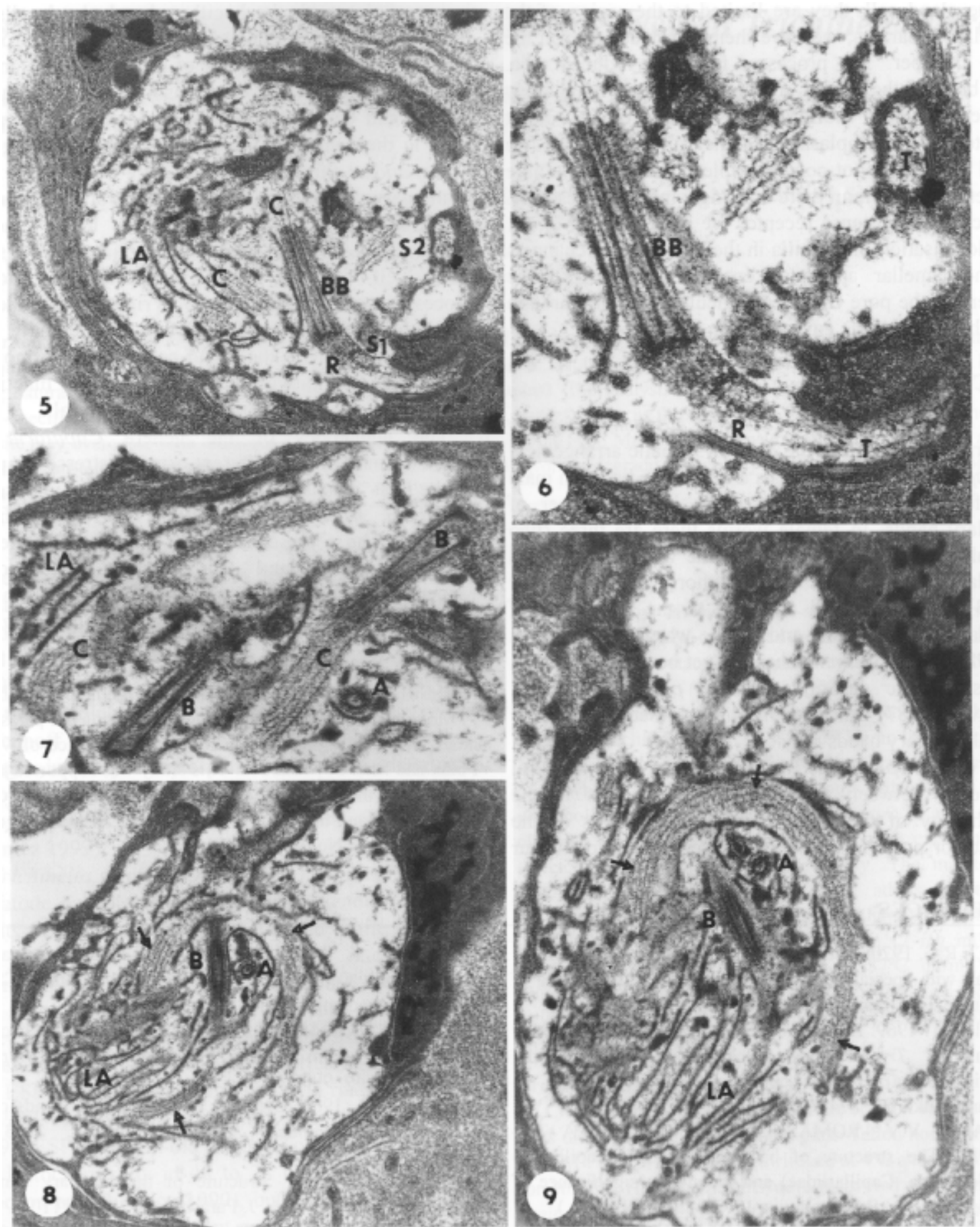

Figs. 5-9. Capillaria pterophylli. Sensory receptors in connection with bacillary band gland cells. Transmission electron micrographs. Fig. 5. Two sensory neuron processes (S1 longitudinal and S2 transversal section) in tight connection with bacillary band gland cell. Note in S1 cross striated ciliary rootlet (R), basal body (BB) and cilium (C) localised among the lamellae of the lamellar apparatus (LA). In S2 note cross sectioned neurotubules, $\times 18500$. Fig. 6. Detail of Fig. 5. Cross striated ciliary rootlet $(\mathrm{R})$, basal body $(\mathrm{BB})$, neurotubules $(\mathrm{T}), \times 38600$. Fig. 7 . Three cilium-derived sensory endings among the lamellae (LA) of a gland cell. A - cross section and B - longitudinal section of basal bodies, $\mathrm{C}-$ cilium, $\times 30400$. Fig. 8. Cross (A) and longitudinal (B) sectioned basal bodies of sensory endings among lamellae (LA) of a gland cell. Note the partly visible cilia (arrows), $\times 18200$. Fig. 9. Serial section to Fig. 8 demonstrating that the cilium (arrows) of the sensory receptor is long and coils among the lamellae (LA) of the lamellar apparatus. Cross (A) and longitudinal (B) sectioned basal body, $\times 23300$. 
of the gland cell, they are limited to the region of the lamellar apparatus; we have them never detected in the pore chamber. The processes represent reduced cilia. The base of the cilium contains a reduced basal body connected with a rudiform cross striated ciliary rootlet inserted in the cytoplasm of the neuron (Figs. 5, 6). The basal body does not contain triplets, but very fine nine duplets. In the cilium there are single microtubules only. The cilia of the sense receptor are rather long (Fig. 9). The localisation of the cilia in the extracellular channels of the lamellar apparatus enables contact with the content of the pore chamber, cuticular pore and through it with the nematode environment.

\section{DISCUSSION}

In Capillaria pterophylli as in Calodium hepaticum (determined according the older systematic arrangement as Capillaria hepatica) exists a difference between male and female worms (Wright 1963) in the number of bacillary bands. In female worms there are three (two lateral and one ventral) and in male worms two lateral bacillary bands only. Other authors, except Wright (1963), have not paid attention to the difference of bacillary bands in male and female worms (Lomakin et al. 1983). This difference has not yet been mentioned in any systematic description of $C$. pterophylli either. Moravec (1987) describes in both male and female the lateral bacillary bands only.

In C. pterophylli there is no apparent ultrastructural difference between male and female worms in the morphology of the bacillary band gland cells of the anterior or posterior regions. The sense receptors occur in association with the bacillary band gland cells in a limited part of the nematode body, i.e. in the proximal body part between the level of the nerve ring and the end of stichosome. In comparison with the results of Wright and Chan (1973) in Calodium hepaticum, this zone in the nematode under investigation is longer. In $C$. hepaticum this zone extends only between the level of the nerve ring and the most anterior stichocyte of the stichosome. In $C$. pterophylli two to four cylindrical cilium-derived sensory processes project into a single gland cell, whereas in $C$. hepaticum four to six processes occur. According to Wright (1968) the two cell types of the bacillary band undoubtedly have different functions - the gland cells help in osmotic or ionic regulation, the non-glandular cells may function in cuticle formation and storage of food material.

The nematodes of the genera Capillaria and Trichuris may reflect different osmotic stresses imposed by the host intestine in comparison to those imposed on Calodium hepaticum inhabiting liver parenchymal spaces. The presence of basal plasmalemma invaginations in gland cells may be related to the reduced area occupied by the bacillary band in Trichuris, as compared to Calodium and Capillaria.

Acknowledgements. We are grateful for the help given by Dr. F. Moravec and Ing. B. Škoríková in collecting the parasitised hosts. We also appreciate the technical assistance of Mr. A. Polák and Mrs. P. Masařová. This study was supported by the grant from the Grant Agency of the Czech Republic No. $524 / 97 / 0009$ and the grant of the Academy of Sciences of the Czech Republic No. K2-022-601.

\section{REFERENCES}

BRUCE R.G. 1970: Trichinella spiralis: fine structure of body wall with special reference to formation and moulting of cuticle. Exp. Parasitol. 28: 499-511.

JENKINS T. 1969: Electron microscope observations of body wall of Trichuris suis Schrank 1788 (Nematoda: Trichuroidea). 1. The cuticle and bacillary band. Z . Parasitenkd. 32: 374-378.

LOMAKIN V.V., ROMASHOV B.V., SERGEEVA T.P. 1983: The structure of bacillary bands of capillariids (Nematoda, Capillariidae) and taxonomic significance of this character. Parazitologiya 17: 24-29. (In Russian.)

McDARBY M.B., WILHELM W.E., LAMOREAUX W.J., CONNS L.B. 1987: Electron microscopy of the body wall of Capillaria catostomi (Nematoda: Capillaridae). Trans. Am. Microsc. Soc. 106: 321-332.

MORAVEC F. 1982: Proposal of a new systematic arrangement of nematodes of the family Capillariidae. Folia Parasitol. 29: 119-132.
MORAVEC F. 1987: Revision of capillariid nematodes (subfamily Capillariinae) parasitic in fishes. Studie ČSAV, No. 3. Academia, Praha, 141 pp.

SHEFFIELD H.G. 1963: Electron microscopy of the bacillary band and stichosome of Trichuris muris and T. vulpis. J. Parasitol. 49: 998-1009.

WRIGHT K.A. 1963: Cytology of the bacillary bands of the nematode Capillaria hepatica (Bancroft, 1983). J. Morphol. 112: 235-250.

WRIGHT K.A. 1968: Structure of the bacillary band of Trichuris myocastoris. J. Parasitol. 54: 1106-1110.

WRIGHT K.A. 1990: Cellular multifunctionality: a capacity facilitating evolutionary change in the paucicellular nematodes. J. Parasitol. 76: 143-144.

WRIGHT K.A., CHAN J. 1973: Sense receptors in the bacillary band of trichuroid nematodes. Tissue Cell 5: 373-380.

Accepted 17 September 1999 